\title{
OPTIMASI SISTEM KOMUNIKASI DARI HT DENGAN HP DALAM PELAKSANAAN TUGAS OPERASI TNI AD MENGGUNAKAN METODE DTMF
}

\author{
Mardianto Teguh Prakasa ${ }^{1}$,Dinar H.S Wahyuni ${ }^{1}$, Nur Rachman ${ }^{2}$, Irfan Mujahidin ${ }^{1}$ \\ 'Jurusan Teknik Elektro UNMER Malang \\ ${ }^{2}$ Departemen Optik dan Hidrolik Lemiantek Kodiklat TNI-AD \\ Email : teguh.perkasa@gmail.com
}

\begin{abstract}
Abstrak
Penggunaan alat komunikasi merupakan kebutuhan pokok TNI AD pada pelaksanaan tugas operasi militer. Sejauh ini pelaksanaan tugas operasi militer TNI-AD di daerah terpencil memiliki kendala yaitu kurang terpantau secara langsung oleh para unsur pimpinan di TNI-AD yang posisinya tidak ada signal. Hal ini disebabkan karena sarana alat komunuikasi yang terbatas diantaranya Handphone (HP) dan Handy Talky (HT) yang belum dapat digunakan sebagai sarana komunikasi pada pelaksanaan operasi militer yang letaknya di daerah tidak ada signal. Dari permasalahan yang ada dibuat suatu penelitian membuat suatu perangkat sistem komunikasi yang dapat berkomunikasi hingga ke daerah yang tidak terangkau oleh sinyal BTS. Dalam penelitian ini, dibuat suatu alat dengan sistem komunikasi dari HT dengan HP menggunakan metode Dual Tone Multi Frekuensi (DTMF). Penelitian ini menggunakan beberapa peralatan diantaranya 3 unit HT, HP, DTMF, mikrokontroler Atmega8, max232, dan wavecom. Sehingga sistem komunikasi dapat dilaksanakan dari dua arah secara full duplex.
\end{abstract}

Kata Kunci : Dual Tone Multi Frekuensi, wavecom, Handy Talky

\section{Pendahuluan}

Di lingkungan militer komunikasi merupakan faktor yang sangat menentukan keberhasilan suatu satuan dalam melaksanakan suatu kegiatan. Menyampaikan suatu informasi ataupun perintah pada pelaksanaan tugas operasi TNI AD memerlukan suatu perangkat yang memadai, agar informasi maupun perintah yang diberikan oleh unsur Komandan dapat diterima dengan jelas oleh pasukan yang berada di lapangan. Dengan semakin berkembangnya ilmu pengetahuan dan teknologi muncul berbagai macam alat komunikasi radio yang bermacam-macam merek beserta keunggulan dan kekurangan masingmasing[1]. Dewasa ini beberapa satuan TNI AD menggunakan alat komunikasi yang sejenis dalam pelaksanaan tugas operasi diantaranya menggunakan komunikasi dari handphone ke handphone dan komunikasi dari radio/HT ke radio/HT. Handphone memiliki keunggulan dapat berkomunikasi dengan jarak yang sangat jauh, tetapi terbatas dengan jangkauan area sinyal BTS[2]. Radio/HT memiliki keunggulan dapat berkomunikasi dimana saja tidak terkecuali area yang tidak terjangkau sinyal BTS Radio/HT juga tetap dapat berkomunikasi, namun Radio/HT tidak dapat berkomunikasi dengan jarak yang jauh. Mengacu pada permasalahan diatas, maka penulis membuat tugas akhir bejudul "Optimasi Sistem Komunikasi Dari Ht Dengan Hp Dalam Pelak-Sanaan Tugas Operasi Tni Ad Menggunakan Metode DTMF"[3]. Tugas akhir ini meningkatkan fungsi dari penelitian sebelumnya yaitu perangkat hanya mampu melaksanakan komunikasi dari HP, namun setelah di optimasi perangkat mampu melaksanakan komunikasi dari HP maupun dari HT[4].

\section{Metode Penelitian}

Metode penelitian dilaksanakan dengan tujuan untuk merancang, meneliti dan mengembangkan suatu penelitian dengan mempertimbangkan kualitas dalam proses sistem komunikasi yang dirancang, selanjutnya proses perancangan dilaksakan secara maksimal agar memperoleh sesuai hasil yang diharapkan. 


\subsection{Variabel Penelitian}

Untuk mengetahui kualitas dari perancangan hardware maka dalam penelitian Optimasi sistem komunikasi ini ada 2 (dua) variabel yang akan diteliti dan dianalisa dengan harapan dapat mengetahui seberapa jauh sistem kerja alat berjalan. Adapun 2 variabel tersebut adalah sebagai berikut:

\subsubsection{Delay}

Delay merupakan keterlambatan dalam waktu transmisi data dari pengirim dan penerima sehingga dapat terlaksana suatu respon pada penerima. Satuan dari delay adalah sekon (detik). Delay dalam perancangan sistem komunikasi ini menjadi salah satu parameter yang akan diteliti.

\subsubsection{Jarak}

Selain bekal strategi perang yang mumpuni, senjata yang handal, dan mental personel yang kuat, harus diakui faktor penting yang jadi penentu keberhasilan dalam pertempuran adalah sistem komunikasi, yaitu sistem komunikasi militer. Jarak disini juga akan menentukan sejauh mana alat akan bekerja dengan baik[5]. Dengan harapan beberapa kali percobaan dengan jarak yang jauh dan dekat dapat dianalisa dan diambil sebuah kesimpulan.

\subsection{Skema Arsitektur Sistem}

Dalam skema arsitektur sistem akan dijelaskan bagaimana cara kerja sistem dan langkah langkah pengujian terhadap parameter yang akan di teliti yaitu delay dan jarak.

\subsubsection{Delay}

Dalam melakukan penelitan terhadap delay yang dihasilkan dari sistem komunikasi dari HT ke HP terdapat langkah-langkah yang akan dilakukan dan digambarkan pada skema 3.1 dibawah ini :

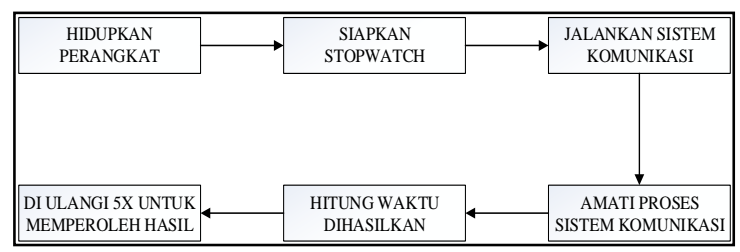

Gambar 2.1 Skema langkah Uji delay

Penjelasan dari skema diatas sebagai berikut:

1. Hidupkan perangkat sistem komunikasi yang akan digunakan percobaan mulai dari Handphone, Handy Talky, wavecom, dan rangkaian PTT.

2. Siapkan 2 rekan kita untuk membantu melaksanakan percobaan dan sediakan stopwatch untuk mengukur time delay pada sistem komunikasi yang akan di teliti.

3. Jalankan sistem komunikasi sesuai langkah - langkah/prosedur.

4. Pada saat wavecom melakukan panggilan/autodial terhadap Handphone nyalakan alat ukut timer digital secara bersamaan. Matikan stopwatch saat output suara keluar pada Hadphone.

5. Hitung delay yang dihasilkan antara suara inputan pada HT dengan output suara pada handphone.

6. Lakukan beberapa kali percobaan dengan proses yang sama untuk mengetahui jumlah akhir apakah hasilnya sama atau berbeda. Kemudian nanti hasilnya akan dijumlahkan secara rata-rata.

\subsubsection{Jarak}

Percobaan pada jarak ini akan dilakukan dengan jarak yang berbeda-beda mulai dari yang terdekat $100 \mathrm{~m}$ sampai $1 \mathrm{Km}$ dengan posisi $\mathrm{Hp}$ penerima berpindah-pindah atau Hand Off di daerah terbuka tanpa halangan[6]. Langkah-langkah yang akan dilakukan dan digambarkan sesuai pada Gambar 3.2 dibawah ini: 


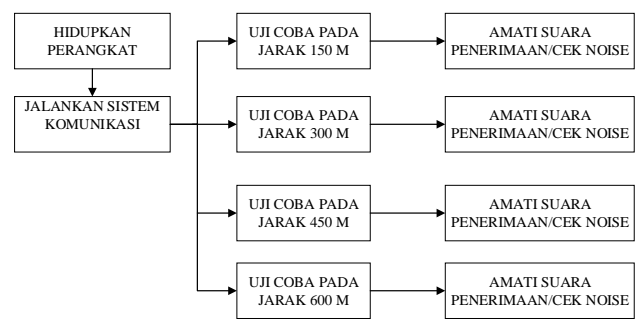

Gambar 2.2 Skema langkah penelitian terhadap Jarak

Penjelasan dari skema diatas sebagai berikut:

1. Hidupkan perangkat sistem komunikasi yang akan digunakan percobaan mulai dari Handphone, Handy Talky, wavecom, dan rangkaian PTT.

2. Siapkan 2 rekan kita untuk membantu melaksanakan percobaan dan sediakan sound level meter digital untuk mengukur noise pada setiap perubahan jarak pada sistem komunikasi yang akan di teliti.

3. Dengan meminta bantuan rekan untuk mengamati hasil suara pada penerima. Maka kita akan melakukan secara hand off. Pada jarak $150 \mathrm{~m}, 300 \mathrm{~m}, 450 \mathrm{~m}$ dan 600m, jalankan sistem komunikasi dan disaat yang sama rekan kita akan mengamati hasil suara pada penerima.

4. Lakukan langkah yang sama tetapi pada jarak yang semakin jauh.

5. Hitung noise yang dihasilkan pada output suara pada handphone

6. Lakukan beberapa kali percobaan dengan proses yang sama untuk mengetahui jumlah akhir apakah hasilnya sama atau berbeda. Kemudian nanti hasilnya akan dijumlahkan secara rata-rata.

\subsubsection{DTMF}

Dalam melakukan penelitan terhadap DTMF yang dihasilkan dari sistem komunikasi dari HT dengan HP terdapat langkah-langkah yang akan dilakukan dan digambarkan pada skema 3.3 dibawah ini:

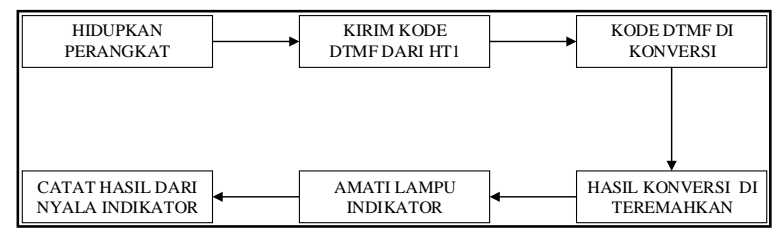

Gambar 3.1 Skema langkah Uji DTMF

Penjelasan skema di atas sebagai berikut:

1. Hidupkan perangkat sistem komunikasi yang akan digunakan percobaan mulai dari Handphone, Handy Talky, wavecom, dan rangkaian PTT.

2. Kirim kode DTMF dari HT1 dengan cara tekan PTT bersamaan dengan salah satu angka pada HT(1 s.d 13) kemudian tekan PTT lalu tekan enter .

3. Kode yang dikirim dari HT1 diterima HT2 dan di konversi oleh DTMF decoder MT8870.

4. Amati lampu indikator yang menyala pada DTMF decoder MT8870 yang menunjukan bahwa kode DTMF yang dikirim telah diterima.

5. Lakukan beberapa kali percobaan dengan proses yang sama untuk mengetahui jumlah akhir apakah hasilnya sama atau berbeda.

6. Catat hasil nyala lampu indikator dari percobaan pertama sampai dengan selesai, dari pengiriman kode 1 s.d 13 .

\subsection{Perancangan Hardware dan Software}

Dalam perancangan alat terdapat alat bahan yang akan digunakan dan spesifikasi yang terdapat pada alat yang digunakan serta flow chart beserta menjelaskan secara keseluruhan alat bekerja. 


\subsubsection{Perancangan Hardware}

\section{A. Perancangan DTMF}

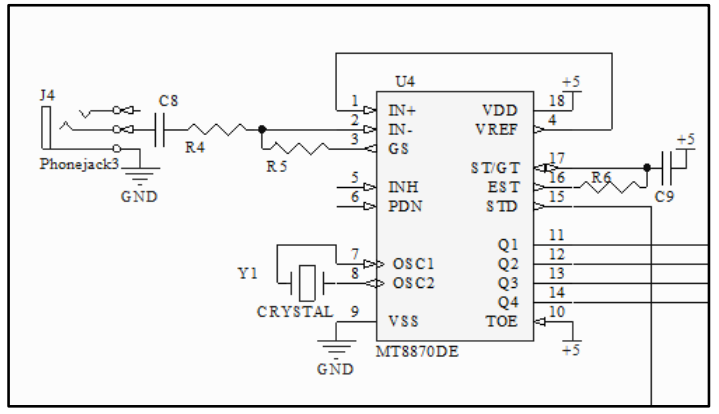

Gambar 2.4 minimum sistem modul DTMF

Dual Tone Multiple Frequency (DTMF) adalah teknik mengirimkan angka angka pembentuk nomor telpon yang di kodekan dengan 2 nada yang dipilih dari 8 buah frekuensi yang sudah ditentukan. Namun penelitian ini kode DTMF yang berupa tone dikirimkan dari sebuah perangkat HT[7]. Awal mulanya Kode DTMF dikirim dari HT1 ke HT2 yang selanjutnya kode tersebut diterjemahkan dalam bentuk biner. Jadi DTMF encoder berfungsi untuk menerjemahkan kode DTMF yang dikirim dari HT1.

\section{B. Perancangan Mikrokontroler}

Mikrokontroler yang digunakan pada penelitian ini adalah Mikrokontroler ATMega8. Atmega8 merupakan Mikrokontroler keluaran dari Atmel Corporation. Mikrokontrol tipe ini termasuk dalam jenis AVR (Alf and Vegard's Risc processor).

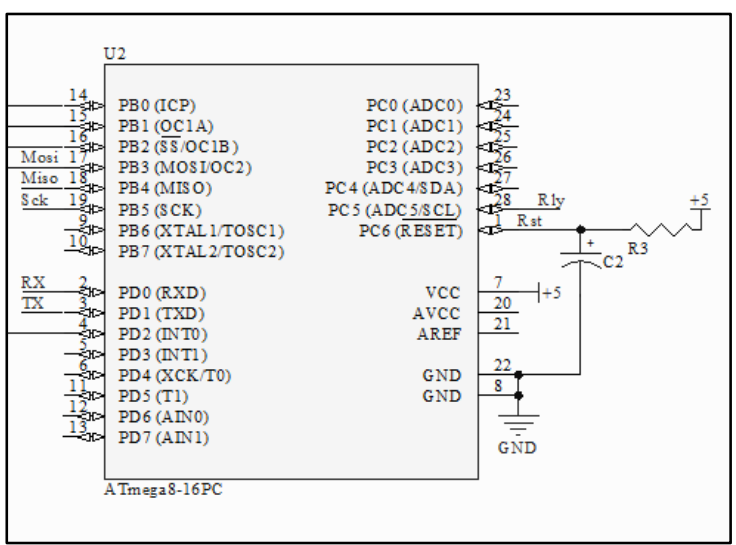

Gambar 2.5 mikrokontroler Atmega8

Pada penelitian ini pin PB0, PB1, PB2, dan PB3 pada mikrokontroler merupakan pin yang digunakan sebagai jalur komunikasi dengan rangkaian DTMF, selain itu ada pin yang digunakan sebagai jalur interrupt yaitu pin PD2 sebagai interupt0[8]. Kemudian pin PC5 berfungsi mengaktifkan relay untuk menekan PTT pada HT pada saat komunikasi berlangsung. Pin PD0 sebagai RX dan PD1 sebagai TX, berfungsi sebagai jalur komunikasi data serial dengan wavecom.

\section{Perancangan Wavecom}

Pada perancangan wavecom data jalur komunikasi antara pin yang terdapat pada DB15 dengan DB9, DB9 dengan RJ11, dan DB15 dengan RJ11 beserta keterangannya. Konektor DB15 merupakan jalur yang digunakan pada Wavecom untuk berkomunikasi dengan rangkaian mikrokontroler. Konektor DB9 merupakan jalur yang digunakan pada rangkaian mikrokontroler untuk berkomunikasi dengan wavecom. Konektor RJ 11 adalah konektor yang dipergunakan dalam jaringan telepon, namun dalam penelitian ini RJ 11 digunakan sebagai jalur audio antara wavecom dengan HT. Pemanfaatan koneksi/port pada wavecom yaitu dengan menghubungkan pin output suara (speaker) pada HT dengan pin input suara 
(microphone) pada wavecom dan menghubungkan output suara (speaker) pada wavecom ke input suara (microphone) pada HT sehingga terjadilah komunikasi.

\subsection{Rancangan Penelitian}

Rancangan ini akan menjelaskan bagaimana rancangan keseluran pada alat, baik dari rancangan perangkat keras maupun perangkat lunak. Dengan membuat rancangan penelitian ini dapat membatu penelitian agar sesuai dengan yang akan dirancang pada sistem kerja alat.

\subsubsection{Perancangan Keseluruhan Alat}

Pada Gambar 3.6 menjelaskan tentang cara kerja dari perangkat sistem komunikasi dari HT ke HP. Pada proses sistem komunikasi dimulai dengan menghidupkan/aktifkan perangkat sistem komunikasi, selanjutnya PTT pada HT3 di tekan secara bersamaan dengan salah 1 tombol yang ada pada HT tersebut untuk mengirim kode DTMF ke HT2

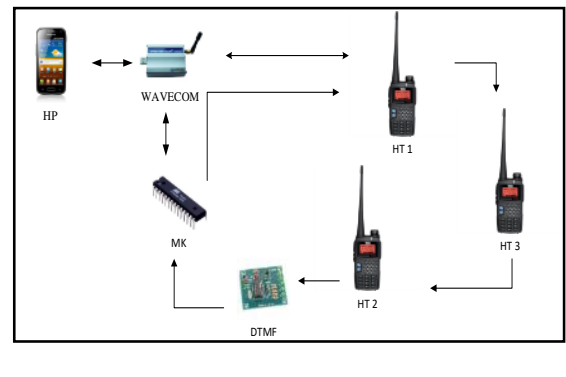

Gambar 2.6 Blok Diagram

Kode DTMF yang di terima HT2 di konversi oleh DTMF decoder menjadi bilangan biner, hasil dari bilangan biner akan di terjemahkan oleh mikrokontroler untuk melakukan panggilan ke nomor HP yang sudah terdaftar/tersimpan pada wavecom, selanjutnya mikrokontroler akan memberikan perintah AT Command berupa Autodial yaitu panggilan otomatis ke nomor yang sudah terdaftar, maka PTT pada HT1 on kemudian HP akan dapat menerima panggilan yang dilakukan oleh wavecom.

\subsubsection{Flowchart dan penjelasan}

Flowchart pada gambar 3.7 menjelaskan tentang cara kerja dari perangkat sistem komunikasi dari HT ke HP. Pada proses sistem komunikasi dimulai dengan menghidupkan/aktifkan perangkat sistem komunikasi, Prajurit TNI yang sedang melaksanakan tugas operasi pemegang HT3 menekan salah satu tombolnya bersamaan dengan PTT, setelah itu masuk ke tahap inisialisasi serial oleh mikrokontroler digunakan untuk komunikasi dengan wavecom, kemudian inisialisasi i/o digunakan untuk menekan PTT, dilanjutkan pembacaan DTMF yaitu kode DTMF dikirim dari HT3 ke HT2, kode tersebut dikonversi oleh DTMF decoder menjadi biner, kemudian biner diterjemahkan oleh mikrokontroler untuk melakukan panggilan ke nomor HP yang sudah tersimpan setelah DTMF terbaca, maka mikrokontroler akan memberikan perintah AT Command berupa Autodial yaitu panggilan otomatis ke nomor yang sudah terdaftar, selanjutnya PPT pada HT1 on maka wavecom dapat melakukan panggilan ke HP. Tetapi jika kode DTMF yang dikirim HT3 maka proses kembali lagi pada tahap pembacaan kode DTMF. 


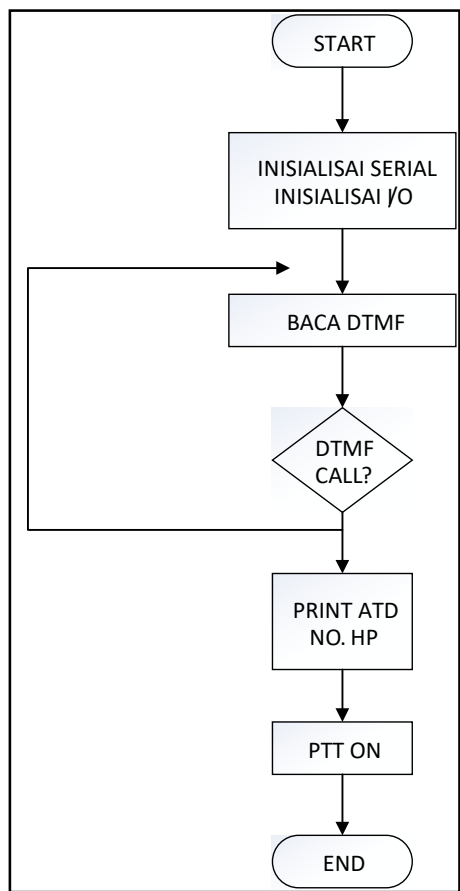

Gambar 2.7 Flowchart Sistem komunikasi

\subsubsection{Perancangan Software}

Software yang direncakan adalah Bascom AVR. Bascom Avr adalah salah satu tool untuk pengembangan / pembuatan program untuk kemudian ditanamkan dan dijalankan pada mikrokontroler,terutama mikrkontroler keluarga AVR[9].

\section{HASIL DAN ANALISIS}

Setelah perancangan alat selesai, maka dilakukan pengujian untuk mengetahui apakah alat yang telah dirancang dan dibuat berjalan seperti yang telah direncanakan. Pengujian dilakukan untuk membandingkan hasil perancangan teoritis dengan hasil percobaan atau pengujian. Dari hasil pengujian dapat diketahui apakah alat telah bekerja sesuai dengan spesifikasi yang diinginkan.

\subsection{Hasil Pengujian dan Analisa Delay} tabel 3.1.

Dalam pengujian ini dilakukan pada jalan yang lurus tanpa halangan, percobaan pada

Tabel 3.1 Hasil Pengujian Delay

\begin{tabular}{|c|c|c|c|c|c|c|c|}
\hline \multirow{2}{*}{ No } & \multirow{2}{*}{ Jarak $(\mathrm{m})$} & \multicolumn{7}{|c|}{ Percobaan (detik) } & \multirow{2}{*}{ Rata- rata (s) } \\
\cline { 3 - 8 } & & 1 & 2 & 3 & 4 & 5 & \\
\hline 1 & 150 & 0,11 & 0,13 & 0,12 & 0,11 & 0,10 & 0,114 \\
\hline 3 & 300 & 0,14 & 0,14 & 0,13 & 0,11 & 0,11 & 0,126 \\
\hline 4 & 450 & 0,22 & 0,17 & 0,21 & 0,17 & 0,20 & 0,194 \\
\hline & 600 & 0,22 & 0,23 & 0,21 & 0,23 & 0,27 & 0,232 \\
\hline
\end{tabular}

Dari hasil tabel diatas dapat kita lihat setiap pengambilan data waktu yang di hasilkan menunjukkan nilai rata-rata yang berbeda - beda pada setiap jaraknya. Dan diperoleh nilai delay rata-rata dari percobaan secara keseluruhan sebesar 0,166 detik.

\subsection{Hasil Pengujian Noise dan Analisa}

Pada pengujian Noise dilakukan dengan mengukur output suara pada HP dengan alat ukur digital sound level meter dengan satuan $\mathrm{dB}, \mathrm{dB}$ merupakan satuan ukur yang digunakan untuk menunjukkan efek dari sebuah perangkat terhadap kekuatan/daya pancar suatu signal[10].

Tabel 3.2 Hasil Pengujian Noise 


\begin{tabular}{|c|c|c|c|c|c|c|c|}
\hline \multirow{2}{*}{ No } & Jarak & \multicolumn{7}{|c|}{ Percobaan (dBA) } & \multirow{2}{*}{ Rata - rata(dB) } \\
\cline { 3 - 7 } & $(\mathrm{m})$ & 1 & 2 & 3 & 4 & 5 & 85,46 \\
\hline 1 & 150 & 81,4 & 82,8 & 93,5 & 85,3 & 84,3 & 83,12 \\
\hline 2 & 300 & 81,2 & 82,0 & 82,9 & 84,2 & 85,3 & 84,12 \\
\hline 3 & 450 & 84,7 & 83,6 & 81,9 & 86,9 & 83,5 & 85,88 \\
\hline 4 & 600 & 84,6 & 82,6 & 82,5 & 93,5 & 86,2 & \\
\hline
\end{tabular}

Dari hasil tabel diatas dapat kita lihat setiap pengambilan data noise yang di hasilkan menunjukkan nilai rata-rata yang berbeda - beda pada setiap jaraknya. Dari data yang diperoleh dari pengujian pada tabel di atas masih perlu dilaksanakan perhitungan pengurangan pada sumber bunyi/terukur yaitu $88.5 \mathrm{~dB}$ dan background noise/diukur yaitu data dari percobaan pada tabel 4.2. Sehingga menghasilkan data pada tabel 4.3 berikut ini. Dan diperoleh nilai noise rata-rata dari percobaan secara keseluruhan pada tabel 4.3 sebesar 87.15 .

Tabel 3.3 Hasil Pengurangan Noise

\begin{tabular}{|c|c|c|c|c|c|c|c|}
\hline \multirow[b]{2}{*}{ No } & \multirow{2}{*}{$\begin{array}{c}\text { Jarak } \\
(\mathrm{m})\end{array}$} & \multicolumn{5}{|c|}{ Percobaan (dBA) } & \multirow{2}{*}{ Rata - rata $(\mathrm{dB})$} \\
\hline & & 1 & 2 & 3 & 4 & 5 & \\
\hline 1 & 150 & 87.5 & 87.5 & 87.5 & 86.5 & 87.5 & 87.3 \\
\hline 2 & 300 & 87.5 & 87.5 & 87.5 & 87.5 & 86.5 & 87.3 \\
\hline 3 & 450 & 86.5 & 87.5 & 87.5 & 85.5 & 87.5 & 86.9 \\
\hline 4 & 600 & 86.5 & 87.5 & 87.5 & 87.5 & 86.5 & 87.1 \\
\hline & \multicolumn{6}{|c|}{ Nilai Rata - rata } & 87.15 \\
\hline
\end{tabular}

Dari hasil data percobaan di atas menunjukkan bahwa nilai noise terendah $81.2 \mathrm{~dB}$ dan Noise tertinggi pada $118.5 \mathrm{~dB}$, dan pada nilai noise 118.5 penerima tidak dapat mendengar suara yang dikirim[11].

\subsection{Hasil pengujian Suara}

A. Pengujian Input suara dari HP

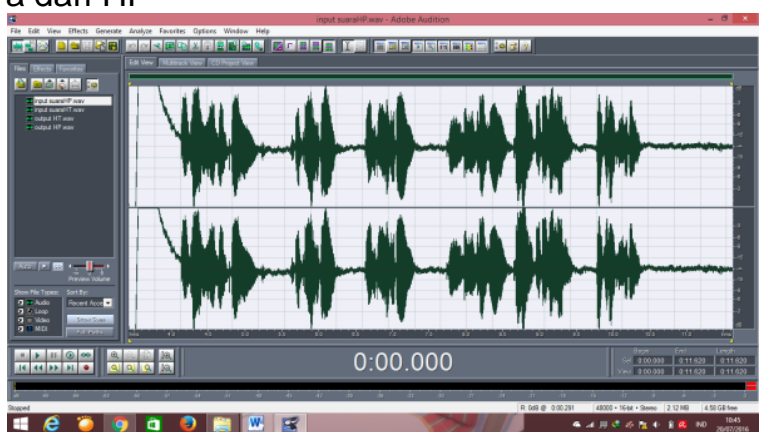

Gambar 3.1Input Suara HP

B. Pengujian Input suara dari HT

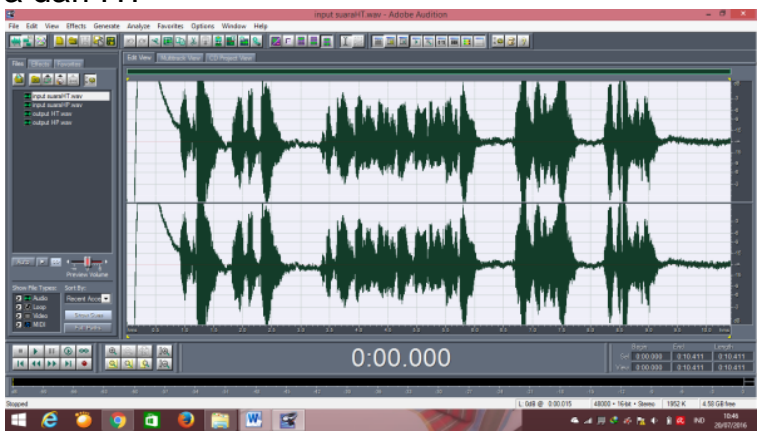

Gambar 3.2 Input suara HT

C. Pengujian Output suara pada HT 


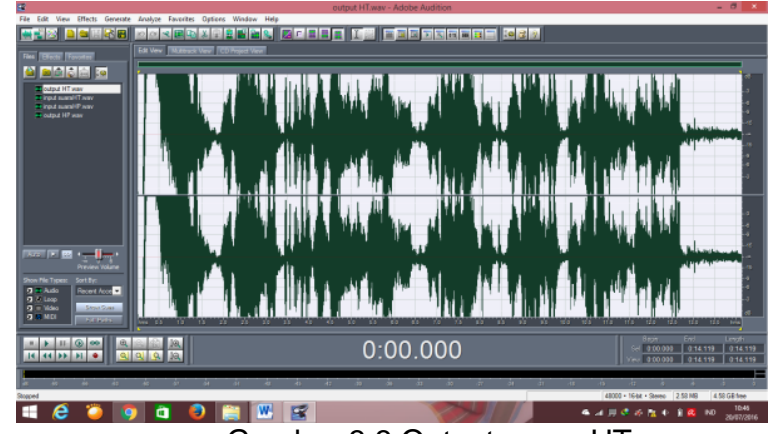

Gambar 3.3 Output suara HT

D. Pengujian Output suara pada HP

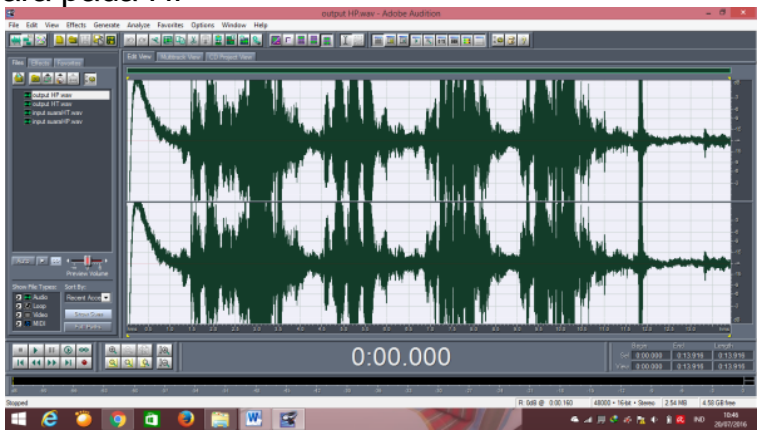

\subsection{Hasil Pengujian DTMF}

Gambar 3.2 Output suara HT

Hasil penguijan DTMF dapat diketahui dari lampu pada DTMF decoder yang telah menerima kode yang dikirim dari HT kemudian di konversi dan diterjemahkan oleh mikrokontroler sehingga lampu indikator menyala.

Tabel 3.3 Hasil Pengujian DTMF

\begin{tabular}{|l|c|c|c|c|c|}
\hline \multicolumn{2}{|c|}{ Input } & \multicolumn{5}{|c|}{ Output } \\
\hline No & Tombol & Q1 & Q2 & Q3 & Q4 \\
\hline 1 & 1 & 0 & 0 & 0 & 1 \\
\hline 2 & 2 & 0 & 0 & 1 & 0 \\
\hline 3 & 3 & 0 & 0 & 1 & 1 \\
\hline 4 & 4 & 0 & 1 & 0 & 0 \\
\hline 5 & 5 & 0 & 1 & 0 & 1 \\
\hline 6 & 6 & 0 & 1 & 1 & 0 \\
\hline 7 & 7 & 0 & 1 & 1 & 1 \\
\hline 8 & 8 & 1 & 0 & 0 & 0 \\
\hline 9 & 9 & 1 & 0 & 0 & 1 \\
\hline 10 & 0 & 1 & 0 & 1 & 0 \\
\hline 11 & Menu & 1 & 1 & 0 & 1 \\
\hline 12 & Enter & 1 & 1 & 1 & 0 \\
\hline 13 & Vfo/Mr & 1 & 1 & 1 & 1 \\
\hline
\end{tabular}

\section{Kesimpulan}

Setelah melalui tahap perencanaan, pembuatan dan pengujian alat terdapat beberapa hal yang dapat disimpulkan, yaitu:

1. Hasil delay rata-rata yang diperoleh setelah melaksanakan beberapa kali percobaan adalah 0,166 detik. Hal ini menunjukkan bahwa pada saat sistem komunikasi berlangsung masih terdapat adanya delay.

2. Hasil pengujian noise didapat setelah melaksanakan beberapa kali percobaan yaitu pada jarak $150 \mathrm{~m}, 300 \mathrm{~m}, 450 \mathrm{~m}, 600 \mathrm{~m}$ didapatkan hasil noise rata-rata $87,15 \mathrm{~dB}$. Ketika pengujian pada jarak lebih dari $600 \mathrm{~m}$ tidak berhasil dikarenakan HT tidak dapat mengirim kode DTMF pada jarak lebih $600 \mathrm{~m}$.

\section{Daftar Pustaka}


[1] A. Harjanto, "Rancang Bangun Aplikasi Pengenalan File Gambar Bitmap Menggunakan Metode Backpropagation," J. JUPITER, 2018.

[2] I. Mujahidin, "Directional $1900 \mathrm{MHz}$ Square Patch Ring Slot Microstrip Antenna For Wcdma," JEEMECS (Journal Electr. Eng. Mechatron. Comput. Sci., 2019.

[3] Sumardi, "Perancangan Sistem Starter Sepeda Motor Menggunakan Aplikasi Android Berbasis Arduino Uno," in Prosiding Seminar IImu Komputer dan Teknologi Informasi, 2017.

[4] I. Mujahidin, R. Yuwono, and A. Mustofa, "Rancang Bangun Rectifier Antenna Mikrostrip Ufo Pada Frekuensi Ultra Wideband (UWB) Sebagai Pemanen Energi Elektromagnetik," $J$. Mhs. TEUB, vol. 3, no. 2, 2015.

[5] I. Mujahidin, S. H. Pramono, and A. Muslim, "5.5 Ghz Directional Antenna with 90 Degree Phase Difference Output," 2019.

[6] A. Faroqi, A. Fitriadi, and N. U. Adiningsih, "Sistem Kendali Pintu Rumah Menggunakan SMS Gateway Berbasis Arduino Uno dan Sensor Ultrasonik," TELKA - Telekomun. Elektron. Komputasi dan Kontrol, 2018.

[7] R. Yuwono, I. Mujahidin, A. Mustofa, and Aisah, "Rectifier using UFO microstrip antenna as electromagnetic energy harvester," Adv. Sci. Lett., 2015.

[8] W. Arianti, A. Affandi, and D. S. Rahardjo, "Rancang Bangun Layanan Internet Protocol Television (IPTV) Terintegrasi Pada Jaringan IPTV Publik," Jur. Tek. Elektro, Fak. Teknol. Ind. Inst. Teknol. Sepuluh Novemb., 2012.

[9] A. Silvia, Haritman \& Muladi, "Rancang Bangun Akses Kontrol Pintu Gerbang Berbasis Arduino Dan Android," Electrans, 2014.

[10]I. Oktariawan, Martinus, and Sugiyanto, "Pembuatan Sistem Otomasi Dispenser Menggunakan Mikrokontroler Arduino Mega 2560," J. FEMA, 2013.

[11]F. Zahro Aska, D. Satria, and W. Kasoep, "Implementasi Radio Frequency Identification (RFID) Sebagai Otomasi Pada Smart Home," Fak. Teknol. Inf. Univ. Andalas, 2012.

\section{Daftar Riwayat Hidup}

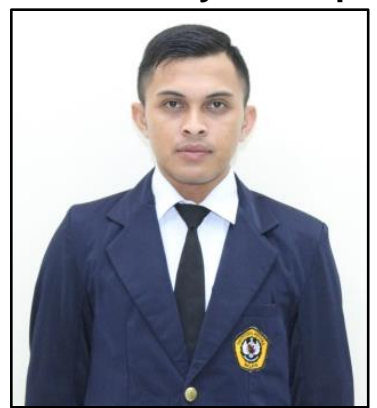

Mardianto Teguh Prakasa, lahir di Lumaang 8 Maret 1990, agama Islam. Penulis menamatkan pendidikan di SDN Dawuhan Lor 12002. Setelah itu Penulis melanjutkan pada jenjang pendidikan SLTP di SMPN 1 SUKODONO dan lulus tahun 2005. Pada tahun 2005 penulis menamatkan pendidikan di SMAN 1 LUMAJANG lulus pada 2008. Atas anugerah ALLAH SWT maka penulis dapat melanjutkan pendidikan S1 pada Jurusan Teknik Elektro UNIVERSITAS MERDEKA Malang pada tahun 2013 hingga saat ini. 